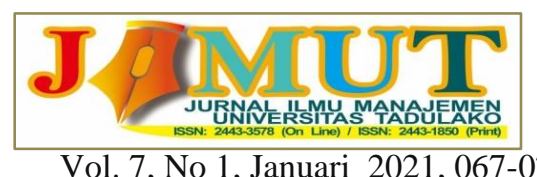

Vol. 7, No 1, Januari 2021, 067-077

\title{
GAYA KEPEMIMPINAN TRANSAKSIONAL DAN MOTIVASI TERHADAP KINERJA KARYAWAN PT. SINAR GALESONG PRATAMA PALU
}

\author{
Misnawati \\ Program Studi S1 Manajemen, Jurusan Manajemen. Fakultas Ekonomi, Universitas Tadulako \\ Email : misnanadjib@gmail.com
}

\begin{abstract}
Misnawati, Research title "The Effect of Transactional Leadership Style and Motivation on Employee Performance at PT. Sinar Galesong Pratama Palu Branch ". Guided by Dr. Idris and Mrs. Harnida Wahyuni Adda. Research title " This study aims to determine the Effect of Transactional Leadership Style and Motivation on Employee Performance at PT. Sinar Galesong Pratama Palu Branch. The independent variables of this study are transactional leadership style (X1) and motivation (X2). while the dependent variable is employee performance $(Y)$. This research method is quantitative descriptive, the type of data used are primary and secondary. The population used in this study were 44 respondents. The research sample is saturated or census sampling. DTA analysis method used is multiple linear regression analysis. The results of this study indicate that the transactional leadership style and motivation simultaneously influence employee performance. Partially the transactional leadership style and motivation influence the performance of employees at PT. Sinar Galesong Pratama Palu Branch.
\end{abstract}

Keywords: transactional leadership, motivation, performance

\section{Abstrak}

Penelitian ini bertujuan untuk mengetahui Pengaruh Gaya Kepemimpinan dan Motivasi Terhadap Kinerja Karyawan Pada PT. Sinar Galesong Pratama Cabang Palu. Variabel independen penelitian ini adalah Gaya Kepemimpinan (X1) Transaksional dan Motivasi (X2). Sedangkan variabel adalah Kinerja Karyawan (Y). Metode penelitian adalah deskriptif kuantitatif, jenis data yang digunakan dalam penelitian ini adalah data kuantitatif. Sedangkan sumber data yang digunakan adalah primer dan sekunder. Populasi yang digunakan dalam penelitian ini sebanyak 44 responden. Sampel penelitian ini yaitu sampling jenuh atau sensus. Metode analisis data yang digunakan dalam penelitian ini adalah analisis regresi linear berganda. Hasil penelitian ini menunjukan bahwa Gaya Kepemimpinan Transaksional dan Motivasi berpengaruh secara serempak terhadap kinerja karyawan. Secara parsial Gaya Kepemimpinan Transaksional dan Motivasi berpengaruh terhadap Kinerja Karyawan Pada PT. Sinar Galesong Pratama Cabang Palu.

\section{PENDAHULUAN}

Setiap perusahaan diharuskan dapat bersaing agar bertahan dalam ketatnyapersaingan global. Salah satu cara agar dapat berkompetisi yaitu memperkuatkapasitas perusahaan dan sumber daya manusia yang dimiliki perusahaan (Sudarmanto, 2009).Sumber daya yang baik dapat diukur dari berbagai aspek seperti kinerja.Menurut Robbins (2006) kinerja adalah bukti keberhasilan seseorang dalamkurung waktu tertentu didalam melaksanakan tugas yang dibandingkan denganberbagai kemungkinan yang akan terjadi.Gaya kepemimpinan transaksional merupakan suatu proses pertukaran yang melibatkan antara pemimpin danbawahan menyebabkan bawahan mendapat imbalan atau penghargaan jika bawahan mampu memenuhi harapan pemimpin serta membantubawahannya mengidentifikasi apa yang harus dilakukan untuk memenuhi hasilyang diharapkan (Bass, 1990 dalam Italiani,2013).Faktor lain yang mempengaruhi kinerja adalah motivasi. Motivasi berfungsi 


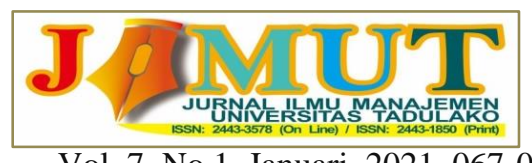

Vol. 7, No 1, Januari 2021, 067-077

sebagaipenggerak yang bersumber dari dalam individu untuk melakukan aktivitastertentu (Sutrisno, 2009). PT. Sinar Galesong PratamaCabang Palu adalah membangun hubungan yang mengutamakan pencapaiankinerja. Tujuan penelitian ini yaitu untuk mengetahui pengaruh variabel gaya kepemimpinan transaksional dan motivasi secara simultan dan parsial pada kinerja karyawan di PT. Sinar GalesongPratama Cabang Palu.

\section{KAJIAN LITERATUR}

\section{Pengertian Kepemimpinan}

Kepemimpinan adalah kemampuan memperoleh konsensusdan keterikatan pada sasaran bersama melalui syarat-syarat perusahaan yangdicapai dengan pengalaman, sumbangan dan kepuasan kerja(Cribbin, 1990 dalam Italiani, 2013). Definisi lainmenyatakan bahwakepemimpinan adalah gaya seorang pemimpin mempengaruhi bawahannya agarmau bekerja sama dan bekerja efektif sesuai dengan perintahnya(Hasibuan, 1986 dalam Italiani, 2013).

\section{Teori Kepemimpinan}

Menurut (Bass dan Avolio, 1997 dalam Ariyana, 2014) dalam artikelnyayang berjudul "The Full Range Of Leadership Development: Basic and Advanced Manual". Menyatakan bahwa dari seluruh model kepemimpinan yang ada padadasarnya dapat dibagi menjadi dua model kepemimpinan utama yaitu:

\section{Gaya Kepemimpinan yang Transformasional}

Kepemimpinan transformasional adalah kepemimpinan yang ideal,memberikan pengembangan pengembangan-pengembangan yang kontemporerdalam menghadapi globalisasi bisnis (Bass dan Avolio, 1997 dalam Ariyana,2014).

2. Gaya Kepemimpinan Transaksional

Kepemimpinan transaksional adalah gaya kepemimpinan yang melibatkansuatu transaksi antar pimpinan dan bawahan yang didasarkan pada pemberdayaan.Pimpinan menjelaskan apa yangperlu dilakukan oleh bawahan sebagai bagian transaksi (Bass dan Avolio, 1997dalam Ariyana, 2014).

\section{Gaya Kepemimpinan Transaksional}

Gaya kepemimpinan transaksional yaitu pemimpin yang memimpin denganmenggunakan pertukaran sosial (Robbins, 2010 dalam Ariyana, 2014).. Kepemimpinan transaksional merupakangaya kepemimpinan dimana pemimpin fokus pada transaksi interpersonal antarapemimpin dengan karayawan sehingga melibatkan hubungan pertukaran (Byciodan Koh, 1995 dalam Ariyana, 2014).

\section{Indikator Gaya Kepemimpinan Transaksional}

Variabel gaya kepemimpinan transaksionalmenggunakan teori (Bass dan Avolio, 1997 dalam Ariyana, 2014) yaitu:

1. Contingent reward (imbalan kontingen), pimpinan memberikan Imbalan kepadaanggota yang telah menyelesaikan dengan teliti tugas yang sudah menjaditanggung jawabnya.

2. Management by exception active (manajemen eksepsi aktif), adalah kondisi dimana pimpinan secaraaktif akan ketat memantau pelaksanaan tugas pekerjaan bawahannya sehinggamereka terhindar dari kesalahan-kesalahan.

3. Management by exception Passive (manajemen eksepsi pasif). Manajer atau pimpinan baru bertindak setelah terjadinya kegagalan yang dilakukan oleh bawahannya, tindakan pemimpin tersebut dilakukan untuk mencapai tujuan organisasi. 
4. Laizez Farie. Pimpinan memberikan kebebasan kepada bawahan agar dapat melakukan tugas pekerjaan tanpa ada pengawasan dari dirinya.

\section{Motivasi}

\section{Pengertian Motivasi}

Motivasi merupakan upaya pemberian daya penggerak yangdiharapkan mampu menciptakan kegairahan kerja seseorang, agar mereka maubekerja sama, bekerja efektif, dan terintegrasi dengan segala daya upayanya (Sutrisno, 2009:111).Proses dengan mana perilaku dibangkitkan, diarahkan dan dipertahankan selamaberjalannya waktu (Porter dan Lawler, 1968 dalam Sedarmayanti, 2011).

\section{Teori Motivasi}

Abraham Maslow, menyatakan bahwa manusiadimotivasi untuk memuaskan sejumlah kebutuhan yang melekat pada diri setiapmanusia yang cenderung bersifat bawaan (Badeni, 2014:79). Di dalam manusia itu ada lima jenjangkebutuhan yang terbentuk dalam suatu hierarki pemenuhan kebutuhan yaitu :

1. Kebutuhan jasmani (Tingkat pertama)

2. Kebutuhan sosial (Tingkat kedua)

3. Kebutuhan pengakuan (Tingkat ketiga)

4. Kebutuhan kenyamanan diri (Tingkat keempat)

5. Kebutuhan aktualisasi diri (Tingkat kelima)

\section{Indikator Motivasi}

Indikator variabel motivasi menggunakan teori yangdisampaikan oleh Abraham Maslow (Badeni 2014:79-81).

1. Kebutuhan Jasmani.Salah satu kebutuhan yang harus dipenuhi oleh seseorang agar mampu mempertahankan diri sebagai makhluk hidup misalnya kebutuhan akan makanan, minuman, perlindungan (pakaian, rumah), seks dan kebutuhan jasmani.

2. Kebutuhan Sosial (Social Needs). Kebutuhan yang berkaitan dengan kebutuhan ingin menjadi bagian dariorang lain, ingin menjadi anggota kelompok tertentu, berhubungan/interaksi dangan orang lain.

3. Kebutuhan Pengakuan. Kebutuhan ini merupakan kebutuhan yang berkaitan dengan kebutuhan ingin diakui keberadaannya oleh orang lain, yaitu: ingin dihormati, dihargai orang lain karena kemampuan atau prestasinya.

4. Kebutuhan Kenyamanan Diri. Kebutuhan ini berhubungan dengan kebutuhan rasa aman terhadap ancaman-ancaman dari luar yang mungkin terjadi.

5. Kebutuhan Aktualisasi Diri. Kebutuhan ini merupakan merupakan kebutuhan yang berhubungan dengan perwujudan diri dalam arti kemampuan/minat/potensi diri dalam bentuk nyata di dalam kehidupan.

\section{Kinerja}

\section{Pengertian kinerja}

Kinerja karyawan (prestasikerja) diberikannya komitmen untuk melakukan tugas yang mempunyai sifatkualitas dan kuantitas secara kualitas dan kuantitas dalam penyelesaian pekerjaanMangkunegara (2007:67).Kinerja merupakan hal yang harus dikerjakan atau tidak dikerjakan olehkaryawan, (Mathis dan Jackson, 2006:65).

\section{Indikator Kinerja}




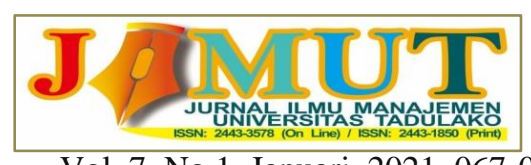

Vol. 7, No 1, Januari 2021, 067-077

Indikator variabel kinerja menggunakan Robbins(2006:260) :

1. Kualitas, tingkat yang dilakukan pekerja yang dilakukan akan menghasilkan pekerjaan yang sesuai dengan syarat dan standar dari pekerjaan yang diharapkan.

2. Kuantitas, hasil yang dicapai yang merupakan satuan dari jumlah unit.

3. Ketepatan waktu, merupakan tingkat kegiatan penyelesaian pekerjaan dari awal mula dilakukan sehingga menjadi hasil pekerjaan. Mampu menuntaskan pekerjaan sesuai dengan ketetapan waktu yang telah disepakati.

4. Efektivitas, merupakan tingkat kemampuan karyawan dalam memaksimalkan sumber daya yang ada agar dapat megembangkan keuntungan dan mengurangi kerugian.

5. Kemandirian, posisi seseorang agar mampu melakukan suatu pekerjaan tanpa mendapatkan bantuan dari orang lain seperti pembimbing atau penguji sera tidak ada campur tangan dari pihak lain tanpa merugikan.

\section{Kerangka Pemikiran}

Pada berbagai bidang khususnya kehidupan berorganisasi, faktor manusia merupakan masalah utama di setiap kegiatan yang ada di dalamnya. Setiap tindakan dan aktivitas dalam sebuah organisasi ditentukan oleh manusia yang ada di dalam wilayah organisasi tersebut. Sumber daya manusia bersumber pada potensi kinerja yang ada dalam perusahaan, juga sebagai penggerak dalam organisasi untuk melakukan aktivitas dalam mencapai tujuan. Oleh karena itu perlu diperhatikan faktor -faktor yang dapat mempengaruhi kinerja karayawan. Dalam penelitian ini gaya kepemimpinan transaksional dan motivasi dipandang sebagai faktor-faktor yang dapat mempengaruhi kinerja karyawan PT. Sinar Galesong Pratama Cabang Palu.

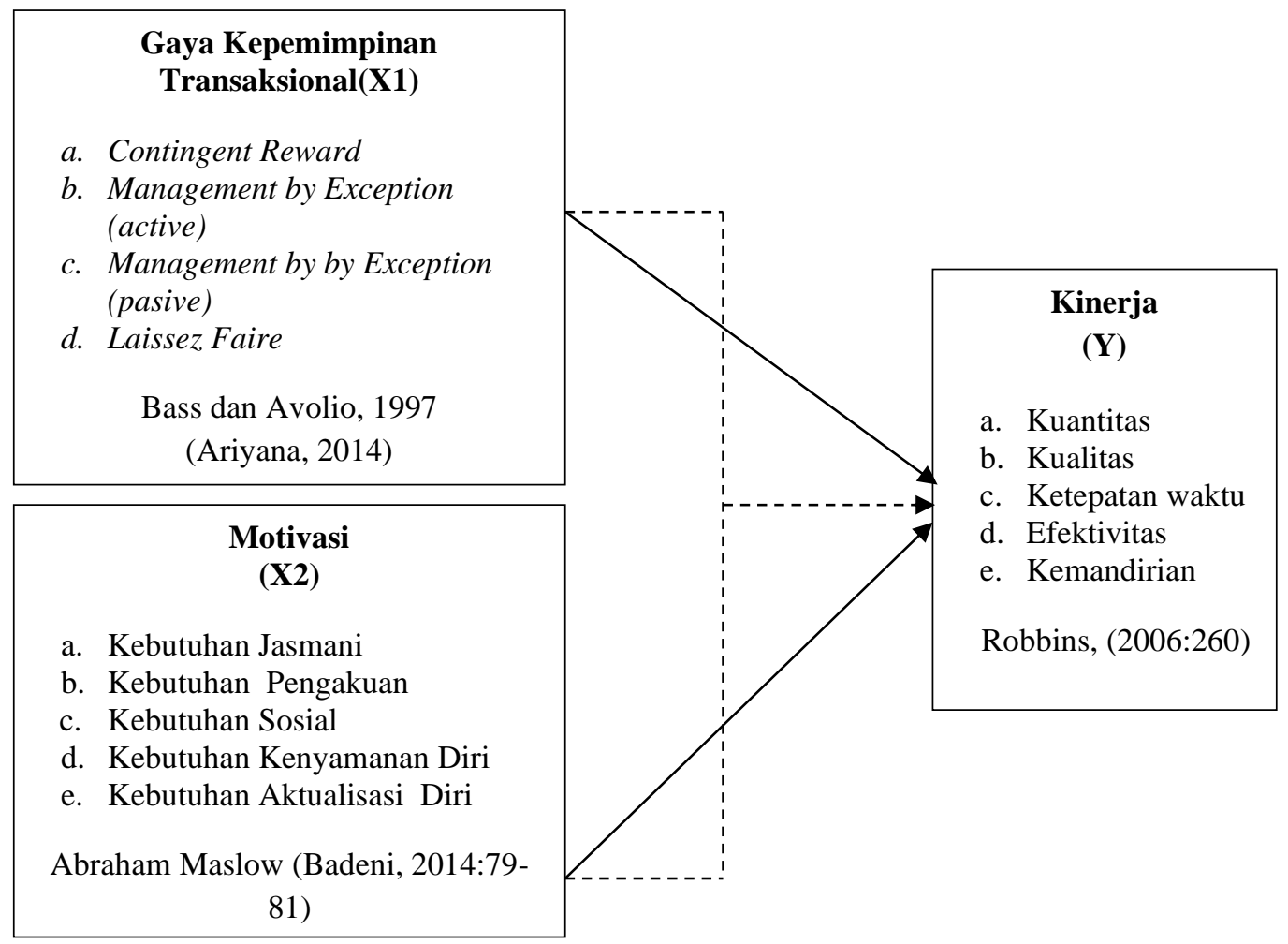

Keterangan:

Pengaruh Simultan: 


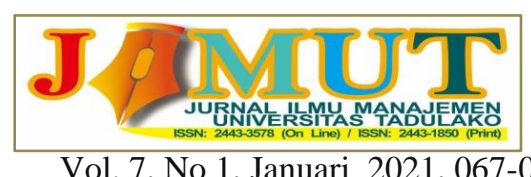

Vol. 7, No 1, Januari 2021, 067-077

Pengaruh Parsial :

\section{Gambar 1 Kerangka Pemikiran}

\section{Hipotesis}

\section{Gaya Kepemimpinan Transaksional Dan MotivasiTerhadap Kinerja Karyawan}

Kepemimpinan transaksional adalah gaya kepemimpinan yangmelibatkan suatu transaksi antar pimpinan dan bawahan yang melibatkanhubungan pertukaran pada kesepakatan mengenai standar kerja, penugasan kerja, dan penghargaan (Bycio dan Koh et.al, 1995 dalamMaulizar, 2012). Variabel gaya kepemimpinan transaksional danmotivasi memiliki hubungan pada kinerja karyawan.

H1: Gaya kepemimpinan transaksional dan motivasi berpengaruh secara simultanterhadap kinerja karyawan pada PT. Sinar Galesong Pratama Cabang Palu.

\section{Gaya Kepemimpinan Transaksional Terhadap Kinerja Karyawan}

Kepemimpinan transaksional mendasarkan diri pada prinsip transaksi ataupertukaran anatara pemimpin dengan bawahan.. Dalam penelitian Maulizar dkk (2012) gaya kepemimpinantransaksional mempunyai hubungan terhadap kinerja karyawan karena dimensi-dimensi gaya kepemimpinan transaksional (imbalan kontigen, manajemen eksepsiaktif, manajemen eksepsi pasif dan laissez faire) semuanya dapat meningkatkankinerja karyawan.

H2: Gaya kepemimpinan transaksional berpengaruh secara parsial terhadapkinerja karyawan pada PT.

Sinar Galesong Pratama Cabang Palu.

\section{Motivasi Terhadap Kinerja Karyawan}

Motivasi adalah suatu faktor yang mendorong seseorang untuk melakukansuatu aktivitas tertentu, oleh karena itu motivasi dapat diartikan sebagai faktorpendorong perilaku karyawan. Untuk menggerakan kinerja karyawan agar sesuai yangdikehendaki organisasi tersebut.Dalam penelitian Zulkifli (2016) motivasi sangat erat hubungannyaterhadap kinerja karyawan dimana motivasi dapat meningkatkan kinerjakaryawan.

H3: Motivasi berpengaruh secara parsial terhadap kinerja karyawan pada PT.Sinar Galesong Pratama Cabang Palu.

\section{METODE PENELITIAN}

\section{Jenis Penelitian}

Jenis penelitian yang digunakan dalam penelitian ini adalah deskriptif dan kuantitatif. Penelitian deskriptif artinya memberikan pemaparan dalam bentuk interpretasi dalam pengaruh gaya kepemimpinan trasaksional dan motivasi terhadap kinerja karyawan pada PT. Sinar Galesong Pratama Cabang Palu.

\section{Lokasi Penelitian}

Tempat penelitian ini adalah PT. Sinar Galesong Pratama Cabang Palu diJl. Yosudarso Kecamatan Mantikulore.
Jenis Data
Jenis data yang digunakan dalam penelitian ini adalah sebagai berikut:
1. Data kualitatif, merupakan data dalam bentuk kata, kalimat, skema, dan gambar. 
2. Data kuantitatif, merupakan data yang dalam bentuk angka atau data kualitatif yang diangkakan. Data kualitatif yang diangkakan (skoring) misalnya terdapat dalam skala pengukuran/skoring: sangat setuju (5), setuju (4), ragu-ragu (3), tidak setuju (2), dan sangat tidak setuju (1) Sugiono (2009:15).

\section{Sumber Data}

Data merupakan segala sesuatu yang diketahui atau dipercaya memiliki sifat yang dapat memberikan gambaran tentang suatu keadaan atau persoalan Supranto, (2001). Data yang digunakan dalam penelitian ini meliputi:

1. Data primer, Data yang diperoleh penulis secara langsung dari PT. Sinar Galesong Pratama Cabang Palu (jalan Yosudarso) melalui observasi, wawancara, maupun daftar pertayaan.

2. Data sekunder, data penunjang yang berhubungan dengan penelitian yang bersumber dari data primer diolah lebih lanjut emudian disajikan oleh penulis data primer atau orang lain.

\section{Populasi Penelitian dan Teknik Pengambilan Sampel}

Populasi yang dimaksudkan dalam penelitian ini adalah seluruh karyawanPT. Sinar Galesong Pratama Cabang Palu yang berjumlah 44 orang karyawan.

\section{Metode Pengumpulan Data}

Metode pengumpulan data peneliti adalah:

1. Observasi. Teknik pendekatan observasi memiliki ciri spesifik bila dibandingkan dengan wawancara dan kuesioner. Dalam penelitian ini observasi penelitian dilakukan mulai dari tanggal 20 Juli 2017.

2. Wawancara. Wawancara digunakan sebagai salah satu teknik pengumpulan data dalam penelitian ini.

3. Kuesioner. Teknik pengumpulan data yang dilakukan dengan cara memberikan seperangkat pertanyaan atau pernyataan tertulis kepada responden.

\section{HASIL DAN PEMBAHASAN}

\section{Karakteristik Responden}

Jenis kelamin yang menunjukan bahwa mayoritas responden pada PT. Sinar Galesong Pratama Cabang Palu berjenis kelamin laki-laki yaitu sebanyak 36 responden $(81,8 \%)$ dan minoritas responden yang berjenis kelamin perempuan yaitu sebanyak 8 responden $(18,2 \%)$. Pada rentang umur 26-30 tahun memiliki jumlah tertinggi, yaitu 19 responden (43,2 \%).Tingkat pendidikan responden pada PT. Sinar Galesong Pratama Cabang Palu menunjukan bahwa mayoritas memiliki tingkat pendidikan SMA/SMK/Sederajat sebanyak 19 responden $(43,2 \%)$.

\section{Hasil Uji Normalitas}

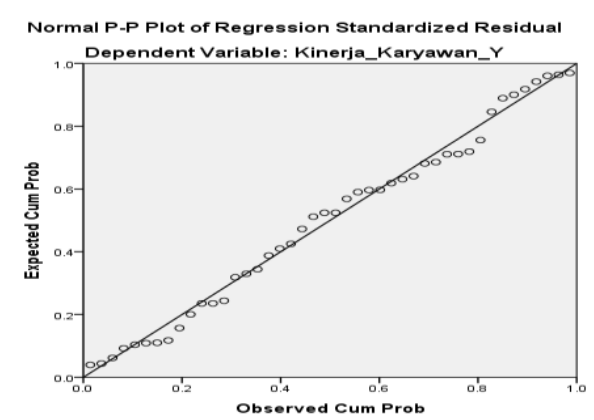

Gambar 2: Hasil Uji Normalitas 
Sumber: Data yang diolah

Variabel dependen atau independen yang mempunyai pendistribusian normal atau mendekati.Jika dilihat dari gambar diatas diketahui data searah dengan garis diagonal maka dari itu variabel tersebut memenuhi syarat uji normalitas.

\section{Uji Heterokedastisitas}

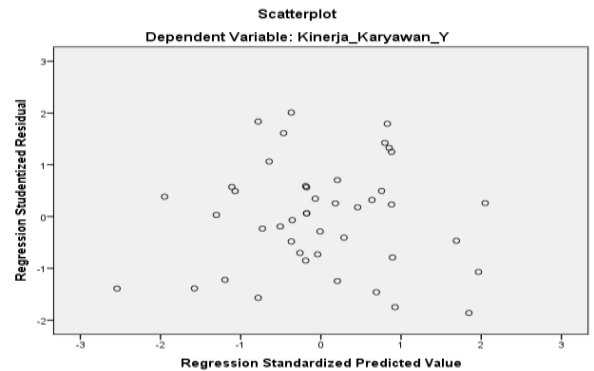

Gambar 3: Hasil Uji Heterokedastisitas

Sumber: Data yang diolah

Uji heterokedastisitas digunakan untuk menguji apakah sebuah model regresi terjadi ketidaksamaan varian dan residual dari satu pengamatan ke pengamatan yang lain. Pada gambar di atas dapat dilihat bahwa titik-titik menyebar dan tidak tidak membentuk pola maka dari dari itu dapat disimpulkan bahwa layak untuk dilanjutkan keanalisis regresi karena tidak terjadinya tidak terjadi nya heteroskadastisitas.

\section{Uji Multikolenearitas}

Tabel 1 Hasil Uji Multikolenearitas

\begin{tabular}{|c|l|c|c|}
\hline \multirow{2}{*}{ No } & \multirow{2}{*}{ Variabel Independen } & \multicolumn{2}{|c|}{ Collinearity Statistic } \\
\cline { 3 - 4 } & & Nilai Tolerance & Nilai VIF \\
\hline 1. & $\begin{array}{l}\text { Gaya Kepemimpinan } \\
\text { Transaksional (X1) }\end{array}$ & 0.575 & 1.739 \\
\hline 2. & Motivasi (X2) & 0.575 & 1.739 \\
\hline
\end{tabular}

Sumber: Data yang diolah

Nilai tolerance dari semua variabel independen $>0,10$ dan Nilai VIF kedua variabel independen tersebut < 10. Dengan demikian, maka dapat disimpulkan bahwa kedua variabel independen tidak terdapat gejala multikolonearitas atau bebas dari masalah multikolonearitas sehingga penelitian ini dapat dilanjutkan ke uji berikutnya.

\section{Hasil Uji Analisis Regresi Linear Berganda}

Analisis regresi linear berganda ini digunakan untuk mencari tau berapa besar pengaruh dari variabel independen $(\mathrm{X})$ terhadap variabel dependen $(\mathrm{Y})$. Dalam penelitian ini, akan di analisis seberapa besar pengaruh variabel $\mathrm{X}$ yaitu Gaya Kepemimpinan Transaksional $\left(\mathrm{X}_{1}\right)$, Motivasi $\left(\mathrm{X}_{2}\right)$ terhadap Variabel kinerja Y. 
Tabel 2 Hasil Uji Analisis Regresi Linear Berganda

\begin{tabular}{|l|c|c|c|}
\hline \multirow{2}{*}{ Model } & $\begin{array}{c}\text { Unstandardized } \\
\text { Coefficients }\end{array}$ & Uji T & Sig \\
\cline { 2 - 3 } & \multicolumn{2}{|c|}{$\mathrm{B}$} & \\
\hline (Constanta) & 0,186 & & \\
\hline $\begin{array}{l}\text { Kepemimpinan } \\
\text { Transaksional (X1) }\end{array}$ & 0,540 & 6.125 & 0,000 \\
\hline Motivasi (X2) & 0,399 & 5,110 & 0,000 \\
\hline Konstanta & $: 0,186 \quad$ F Hitung & $: 90,785$ \\
R & $: 0,903 \quad$ Sig & $: 0,000$ & \\
Adjusted R Square & $: 0,807$ & & \\
R Square & $: 0,816$ & & \\
\hline
\end{tabular}

Sumber: Data yang diolah

Dari tabel diatas dapat diketahui bahwa hasil analisis regresi berganda, jika dimasukkan pada model persamaan regresi adalah sebagai berikut:

$$
\begin{aligned}
& \mathbf{Y}=\boldsymbol{\alpha}+\mathbf{b}_{1} \mathbf{X}_{\mathbf{1}}+\mathbf{b}_{2} \mathbf{X}_{\mathbf{2}} \\
& \mathrm{Y}=0,186+0,540 \mathrm{X}_{1}+0,399 \mathrm{X}_{2}
\end{aligned}
$$

Berdasarkan dari persamaan regresi di atas, maka dapat diketahui bahwa kedua variabel bebas (gaya kepemimpinan transaksional dan motivasi) memiliki penjelasan nilai koefisien sebagai berikut :

a. Nilai konstanta $(\alpha)$ adalah 0,186 , artinya variabel gaya kepemimpinan transaksional $\left(\mathrm{X}_{1)}\right.$ dan motivasi $\left(\mathrm{X}_{2}\right.$, di anggap memiliki hubungan atau tidak mengalami perubahan (bernilai 0) maka kinerja karyawan PT. Sinar Galesong Pratama di Kota Palu memiliki nilai tetap positif 0,186.

b. Nilai koefisien regresi variabel kepemimpinan transaksional $\left(\mathrm{X}_{1}\right)$ adalah positif yaitu sebesar 0,540. Hal ini menyatakan bahwa setiap kenaikan variabel gaya kepemimpinan transaksional (X1) maka variabel kinerja (Y) akan naik sebesar 0,540 dengan asumsi bahwa variabel bebas yang lain dari model regresi adalah tetap.

c. Nilai koefisien regresi variabel motivasi (X2) sebesar 0,399. Hal ini menyatakan bahwa setiap kenaikan variabel motivasi (X2) maka variabel kinerja (Y) akan naik sebesar 0,399 dengan asumsi bahwa variabel bebas yang lain dari model regresi adalah tetap.

\section{Hasil Uji Simultan (Uji F)}

Berdasarkan hasil uji ANOVA (Analysis of Varians) atau F test diperoleh Sig.F sebesar 0,000 < 0,05 yang dapat diartiakan bahwa variabel gaya kepemimpinan transaksional dan motivasi secara simultan berpengaruh terhadap variabel kinerja karyawan.

Tabel 3 Hasil Uji Simultan (Uji F)

\begin{tabular}{|l|r|r|r|r|r|}
\hline \multicolumn{1}{|c|}{ ANOVA $^{\mathrm{b}}$} \\
Model & \multicolumn{1}{|c|}{$\begin{array}{c}\text { Sum of } \\
\text { Squares }\end{array}$} & Df & $\begin{array}{c}\text { Mean } \\
\text { Square }\end{array}$ & \multicolumn{1}{c|}{$\mathrm{F}$} & Sig. \\
\hline 1 Regressio & 3.598 & 2 & 1.799 & 90.78 &, $000^{\mathrm{a}}$ \\
$\mathrm{n}$ & .813 & 41 & .020 & & \\
Residual & 4.411 & 43 & & & \\
Total & & & & \\
\hline
\end{tabular}


a. Predictors: (Constant), X2, X1

b. Dependent Variable: $Y$

Sumber : Data yang diolah

\section{Hasil Uji Parsial (Uji T)}

Tabel 4 Hasil Uji Parsial (Uji T)

Coefficients $^{a}$

\begin{tabular}{|ll|l|l|l|l|l|}
\hline \multirow{2}{*}{ Model } & \multicolumn{2}{|c|}{ Unstandardized Coefficients } & $\begin{array}{c}\text { Standardized } \\
\text { Coefficients }\end{array}$ & \multirow{2}{*}{$\mathrm{T}$} & \multirow{2}{*}{ Sig. } \\
\cline { 3 - 5 } & \multicolumn{2}{|c|}{$\mathrm{B}$} & \multicolumn{1}{|c|}{ Std. Error } & \multicolumn{1}{|c|}{ Beta } & & \\
\hline 1 & (Constant) &, 186 &, 243 & &, 766 &, 448 \\
& X1 &, 540 &, 088 &, 541 & 6,125 &, 000 \\
& X2 &, 339 &, 078 &, 452 & 5,110 &, 000 \\
& & & & & \\
\hline
\end{tabular}

a. Dependent Variable: $Y$

Sumber : Data yang diolah

1. Variabel gaya kepemimpinan transaksional (X1), nilai signifikansinya sebesar 0,000. Karena angka probabilitas signifikansi $<0,05$ maka dengan demikian gaya kepemimpinan transaksional berpengaruh signifikan terhadap kinerja karyawan.

2. Variabel motivasi (X2), nilai signifikansinya sebesar 0,000. Karena angka probabilitas signifikansi $<0,05$ maka dengan demikian motivasi berpengaruh signifikan terhadap kinerja karyawan.

\section{Hasil Koefisien Determinasi $\left(\mathbf{R}^{2}\right)$}

Tabel 5 Hasil Koefisien Determinasi $\left(\mathbf{R}^{2}\right)$

\begin{tabular}{|c|c|c|c|c|}
\hline Model & $\mathrm{R}$ & $\mathrm{R}$ Square & $\begin{array}{c}\text { Adjusted } \mathrm{R} \\
\text { Square }\end{array}$ & $\begin{array}{c}\text { Std. Error of the } \\
\text { Estimate }\end{array}$ \\
\hline 1 &, $903^{\mathrm{a}}$ &, 816 &, 807 &, 14077 \\
\hline
\end{tabular}

a. Predictors: (Constant), X2, X1

b. Dependent Variable: $Y$

Sumber: Data yang diolah

Hasil pengolahan data yang dilakukan dapat dilihat bahwa nilai R dan R Square masing masing 0,903 dan 0,807 dijelaskan sebagai berikut:

1. Nilai R Square atau koefisien determinasi memiliki nilai sebesar 0,816 artinya pengaruh gaya kepemimpinan transaksional dan motivasi terhadap kinerja karyawan PT. Sinar Galesong Pratama adalah sebesar $81,6 \%$, sedangkan $18,4 \%$ dipengaruhi oleh faktor lain

2. Koefisien korelasi (R) memiliki nilai sebesar 0,903 yang artinya bahwa variabel yang diteliti yaitu gaya kepemimpinan transaksional dan motivasi mempunyai hubungan yang kuat dengan variabel terkaitnya sebesar 0,903 atau sebesar $90,3 \%$.

Pembahasan Hasil Penelitian

Pengaruh Gaya Kepemimipinan Transaksional (X1) dan Motivasi (X2) Secara Simultan Terhadap Kinerja Karyawan (Y). 


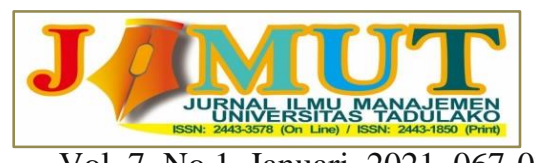

Vol. 7, No 1, Januari 2021, 067-077

Hasil penelitian yang telah dilakukan pada PT. Sinar Galesong Pratama Cabang Palu, diketahui bahwa variabel gaya kepemimpinan transaksional dan motivasi, berpengaruh secara simultan terhadap kinerja karyawan di PT. Sinar Galesong Pratama Cabang Palu. Hal ini juga memberikan arti bahwa gaya kepemimpinan transaksional dan motivasi, dikatakan baik karena memiliki hubungan yang kuat/ tinggi dan saling menunjang sehingga berdampak baik pada kinerja karyawan di PT. Sinar Galesong Pratama Cabang Palu. Pemberian gaji, upah yang sesuai kepada karyawan akan mendorong karyawan tersebut mengerjakan pekerjaannya.

\section{Pengaruh Gaya Kepemimpinan Transaksional (X1) Secara Parsial Terhadap Kinerja Karyawan (Y).}

Hasil penelitian menunjukkan bahwa gaya kepemimpinan transaksional berpengaruh secara parsial dan signifikan terhadap kinerja karyawan di PT Sinar Galesong Pratama Cabang Palu. Hasil dari penelitian ini memberikan arti bahwa masalah gaya kepemimpinan transaksional merupakan salah satu hal yang mendasar dalam peningkatan kinerja karyawan di PT Sinar Galesong Pratama Cabang Palu dalam melaksanakan tugas-tugasnya sebagai jasa pendistribusian produk kendaraan bermotor khususnya kendaraan roda dua merek suzuki.

\section{Pengaruh Motivasi (X2) Secara Parsial Terhadap Kinerja Karyawan (Y).}

Hasil penelitian menunjukkanbahwa motivasi berpengaruh secara parsial dan signifikan terhadap kinerja karyawan pada PT Sinar Galesong Pratama Cabang Palu. Hal ini juga memberikan arti bahwa apabila motivasi ditingkatkan maka kinerja karyawan pada PT Sinar Galesong Pratama Cabang Palu akan meningkat pula. Sesuai dengan hasil yang didapatkan dari jawaban karyawan motivasi memiliki peran penting terhadap kinerja karyawan pada PT Sinar Galesong Pratama Cabang Palu. Motivasi yang dimiliki karyawan sudah baik dilihat dari hasil kerja dan ketepatan waktu dalam menyelesaikan pekerjaan yang diberikan.

\section{KESIMPULAN DAN SARAN}

\section{Kesimpulan}

Kesimpulan dari penelitian ini adalah

1. Variabel gaya kepemimpinan transaksional dan motivasi secara simultan berpengaruh terhadap variabel kinerja karyawan.

2. Variabel gaya kepemimpinan transaksional berpengaruh signifikan terhadap kinerja karyawan.

3. Variabel motivasi berpengaruh signifikan terhadap kinerja karyawan.

\section{Saran}

Berdasarkan hasil penelitian, ada beberapa saran yang dapat diberikan penulis adalah

1. Diharapkan kepada PT. Sinar Galesong Pratama cabang Palu agar lebih memperhatikan gaya kepemimpinan transaksional khususnya pada management by exception passive (melakukan perbaikan setelah kegagalan) karena memiliki kontribusi terendah, dimana karyawan harus diaasi dan diberi arahan untuk memperbaiki pekerjaan yang telah gagal.

2. Diharapkan kepada PT. Sinar Galesong Pratama cabang Palu agar lebih memperhatikan motivasi, khususnya kebutuhan aktualisasi diri (tepat waktu). Dimana karyaan yang datang terlambat harus diberi sanksi yang tegas agar tidak mengulangi kesalahannya.

3. Diharapkan kepada PT. Sinar Galesong Pratama cabang Palu agar lebih memperhatikan kinerja, khususnya ketepatan waktu. Dimana karawan diberi arahan jika telah menyelesaikan pekerjaannya dan masih mempunyai waktu untuk bekerja, dapat membantu karyaan lainnya untuk meyelesaikan pekerjaannya. 


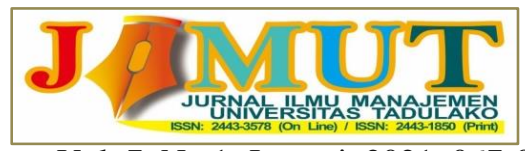

Vol. 7, No 1, Januari 2021, 067-077

\section{REFERENSI}

Anoraga, P. 2001. Psikologi Kerja. Jakarta: PT. Rineka Cipta.

Ariyana, 2014. Pengaruh Gaya Kepemimpinan dan Motivasi Terhadap Kinerja Pegawai Dinas Koperesi, UMKM, Perindustrian dan Perdagangan Daerah Provinsi Sulawesi Tengah. Skripsi,Jurusan Manajemen Fakultas Ekonomi UNTAD Palu.

Badeni, 2014, Kepemimpinan dan Perilaku Organisasi, Bandung: alfabeta.

Ghozali. Imam. (2006). Aplikasi Analisis Multivariate Dengan Program SPSS. Semarang: BP Universitas Diponegoro. Semarang.

Italiani. Adhistya. 2013. Pengaruh Gaya Kepemimpinan Transformasional dan Transaksional Terhadap Kinerja Pegawai Departemen SDM PT. Semen Gresik (PERSERO).Jurnal Ilmu Manajemen, Vol 1, No. 2, Hal:455.

Mangkunegara, AA. Anwar Prabu., 2007. Manajemen Sumber Daya Manusia Perusahaan, Rosda, Bandung.

Mathis, R.L. \& J.H. Jackson. 2006. Human Resource Management: Manajemen Sumber Daya Manusia. Terjemahan Dian Angelia. Jakarta: Salemba Empat.

Maulizar, Musnadi, dan Yunus., 2012. Pengaruh Kepemimpinan Transaksional Dan Transformasional Terhadap Kinerja Karyawan Bank Syariah Mandiri Cabang Banda, Jurnal Manajemen Pascasarjana Universitas Syiah Kuala, Vol. 1, No. 1. Pp. 58-65.

Robbins, S. P. (2006). Perilaku organisasi. Jakarta: PT. Indeks.

Sedarmayanti. 2011. Manajemen Sumber Daya Manusia, Reformasi Birorkrasi dan Manajemen Pegawai Negeri Sipil. Bandung: PT. Refika Aditama.

Sugiono. 2009. Metodologi Penelitian Bisnis. Alfabeta, Bandung

Sudarmanto, 2009. Kinerja dan Pengembangan Kompetensi SDM. Yogyakarta: Pustaka Pelajar.

Sutrisno. Edy, 2009, Manajemen Sumber Daya Manusia, Edisi Pertama, Kencana Prenadamedia Group.

Zulkifli, Suwarno, dan Yuliani. 2016. Pengaruh Kepemimpinan dan Motivasi Terhadap Kinerja Pegawai Pada Dinas Kependudukan dan Catatan Sipil Kabupaten Musi Rawas. Jurnal Adminika, Vol. 2, No.2, Hal:1-19. 